\title{
Applications of acoustic pharyngometry in screening of the sleep-disordered breathing
}

\author{
G. Shivarov \\ юENT Clinic, „Sv. Anna“ Hospital, Varna
}

\begin{abstract}
INTRODUCTION: Acoustic pharyngometry is an inexpensive, quick, non-invasive, and easily repeatable method for localizing the upper airway obstruction in sleep-related breathing disorders.

AIM: The purpose of this study was to describe the general characteristics of the method of acoustic pharyngometry and to illustrate its differential-diagnostic role concerning the extent of the pharyngeal dysfunction for the first time in Bulgaria.

MATERIALS AND METHODS: Between April 1, 2019 and December 31, 2019, a total of 400 adult subjects, 272 males and 128 females, at a mean age of $50.8 \pm 14.1$ years from the city of Varna underwent screening examinations for OSA and snoring by using acoustic pharyngometry with Eccovision ${ }^{\circledR}$ acoustic pharyngometer. The acoustic pharyngometric findings of healthy subjects and patients with pharyngeal dysfunction were illustrated and discussed.

RESULTS: There were considerable differences between the values of the pharyngeal volume, mean and minimal cross-sectional areas and minimal distance in healthy subjects and patients with slightly expressed and severe pharyngeal dysfunction causing sleep-related breathing disorders.

CONCLUSION: The detection of these differences in terms of the main acoustic pharyngometric parameters between normal subjects and patients with pharyngeal dysfunction proves that a much broader acoustic pharyngometry application for the screening and early diagnosis of these socially significant disturbances in Bulgaria is undoubtedly beneficial.
\end{abstract}

Keywords: acoustic pharyngometry, pharyngeal dysfunction, pharyngeal volume, cross-sectional area, sleep-disordered breathing

\section{Introducton}

In recent years, evidence accumulates that acoustic pharyngometry is an inexpensive, quick, noninvasive, and easily repeatable method for locating the upper airway obstruction in sleep-related breathing disorders. The acoustic pharyngometry evaluates the static airway during the waking state when there is neuromuscular activation, but disregards dynamic and sleep state changes (1). It demonstrates a significant difference in upper airway cross-sectional area measurements in individuals with and without obstructive sleep apnea (OSA) which proves its great potential in OSA screening (2). The accuracy and reproducibility of acoustic rhinometry and acoustic pharyngometry for tridimensional assessment of airway caliber in various clinical situations are comparable to computerized tomography and magnetic resonance imaging (3).

The acoustic pharyngometry does not involve exposure to radiation, ensures a real-time display of the upper airway and assesses quantitatively the entire airway simultaneously and rapidly. However, this technique requires certain cooperation from the subject, is difficult to perform during sleep, and does not inform about the nasopharynx. Because polysomnography is not a popular screening tool for OSA worldwide yet, the acoustic pharyngometry is needed to screen the patients by localizing the possible narrowing area and predicting the sleep-disordered breathing at the initial patient's 
visit. The acoustic pharyngometry can't replace polysomnography in OSA evaluation as it does not assess OSA severity. Being a reliable screening tool, this new method helps primary physician making the decision which patients should be referred to specialized sleep centres for further evaluation and treatment of OSA (4).

\section{General characteristics of acoustic pharyngometry}

The acoustic pharyngometry assesses the geometry of the oropharyngeal cavity using a reflected acoustic signal (filtered click) emitted from a device and sent into the oropharynx (5). This principle is based on the relation: $\mathbf{Z}=\mathbf{r C} / \mathbf{A}$ where: $\mathbf{Z}$ is impedance (resistance), $\mathbf{r}$ is gas density traversed by the acoustic wave, $\mathbf{C}$ is the wave velocity, and $\mathbf{A}$ is tube diameter (5). If $\mathbf{r}$ is a constant and $\mathbf{C}$ is equal to 0 , the impedance is inversely proportional to tube cross-section: $\mathbf{A}=1 / \mathbf{Z}$.

The amplitude and frequency of reflected waves depend on the airway area, while the time taken for the reflected wave to return is a function of distance. Therefore the relation 'pressure/time' is changed into 'cross-sectional area/distance' (5). Reductions in the anatomical space and particularly in the diameter produce changes in the intensity of the reflected wave and in the time taken for the reflected wave to return from a given anatomical structure to the microphone (6).

The main components of the acoustic pharyngometry parameters are illustrated in Fig. 1. Here belong the basic characteristics of the cross-sec- tional area of the pharynx: the specific waves mentioned above, the volume of the pharyngeal space, the mean and minimal cross-sectional area, the single areas of the oropharyngeal junction, epiglottis and glottis, the minimal distance as well as the distances of the oral cavity, oropharynx and hypopharynx.

Our aim was to compare the findings detected by using acoustic pharyngometry between healthy adults and adults with sleep-disordered breathing within the recent prevention programme in the city of Varna.

\section{Materials and methods}

Between April 1, 2019 and December 31, 2019, a total of 400 adult subjects, 272 males and $128 \mathrm{fe}-$ males, at a mean age of $50.8 \pm 14.1$ years from the city of Varna participated in the screening examinations for sleep-disordered breathing kindly sponsored by the Sleep Apnea Prevention Programme of the Municipality of Varna. Acoustic pharyngometry with Eccovision ${ }^{\circledR}$ acoustic pharyngometer (HOOD Laboratories, Boston, MA, USA) in sitting position was used for the first time in Bulgaria in the Division of Otorhinolaryngology, St. Anna Hospital of Varna. Several other appropriate diagnostic methods such as clinical inspection, anterior rhinoscopy, pharyngoscopy, indirect laryngoscopy, and acoustic rhinometry were applied by a highly qualified team of otorhinolaryngologists. All the participants filled-in an Epworth Sleepiness Scale questionnaire and reported their concerns related to sleep-related breathing disorders.

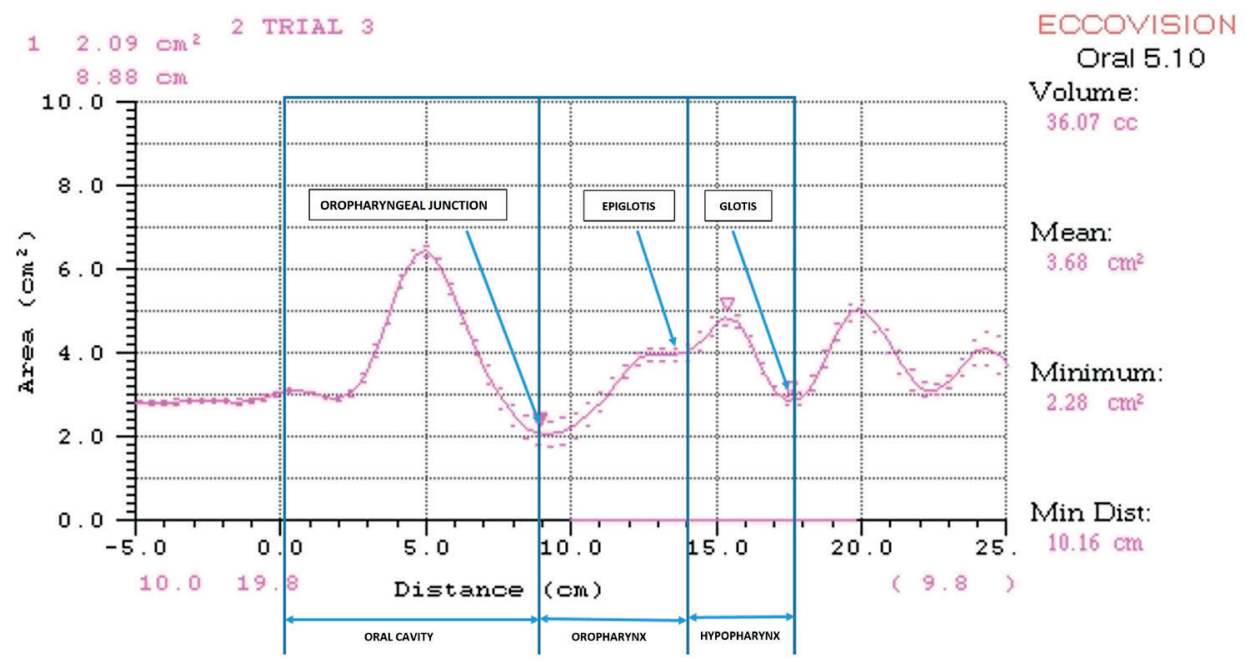

Figure 1. Schematic presentation of the acoustic pharyngometry data 


\section{Results}

In the present study, we illustrated the normal acoustic pharyngometry patterns in adults without any sleep-disordered breathing in comparison with pathological acoustic pharyngometry findings in patients with a slightly expressed and severe pharyngeal dysfunction.

The normal findings from the acoustic pharyngometry examinations in a 35-year old healthy man and a 27 -year old healthy woman were displayed in Fig. 2 and Fig. 3.

The pathological acoustic pharyngometry findings in a 67-year old male patient suffering from arterial hypertension and type 2 diabetes mellitus and diagnosed with slightly expressed pharyngeal dysfunc- tion due to low soft palate, uvula elongation along with nasal septum deviation and chronic hypertrophic rhinitis were demonstrated in Fig. 4.

The pathological acoustic pharyngometry findings in a 47-year old female patient diagnosed with slightly expressed pharyngeal dysfunction due to low soft palate, uvula elongation along with nasal septum deviation and chronic hypertrophic rhinitis were demonstrated in Fig. 5.

The pathological acoustic pharyngometry findings in a 29-year old male patient suffering from arterial hypertension and diagnosed with severe pharyngeal dysfunction due to low soft palate, uvula elongation along with chronic hypertrophic rhinitis were demonstrated in Fig. 6.

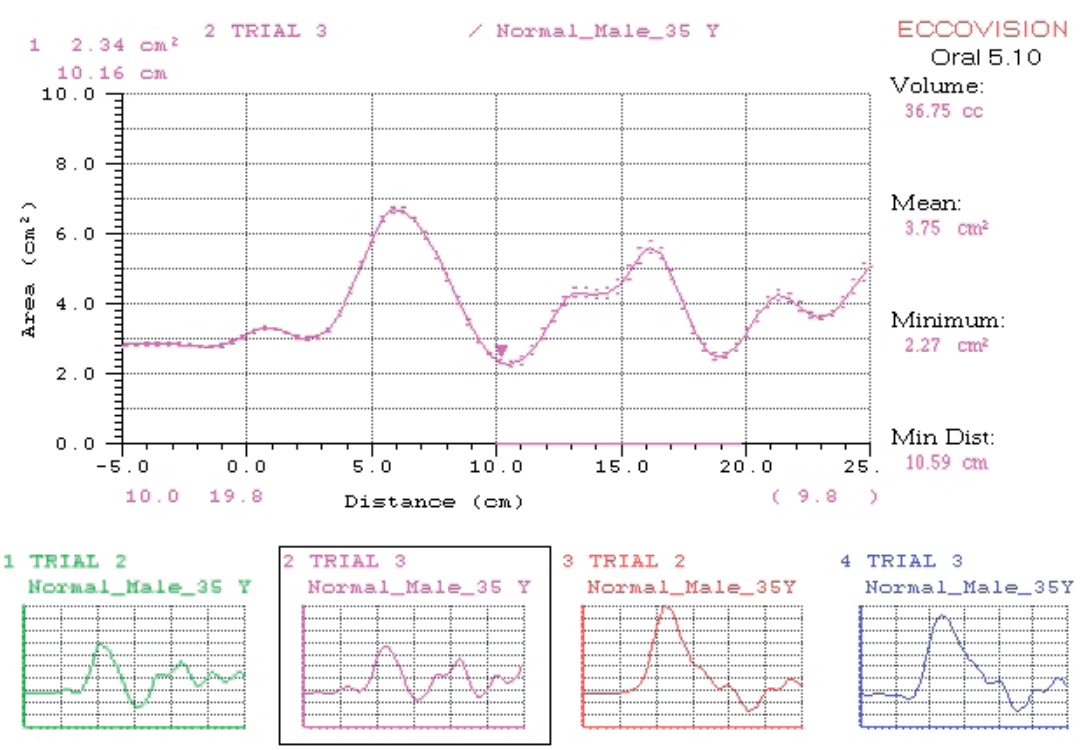

Figure 2. A normal acoustic pharyngometry image of a healthyman.

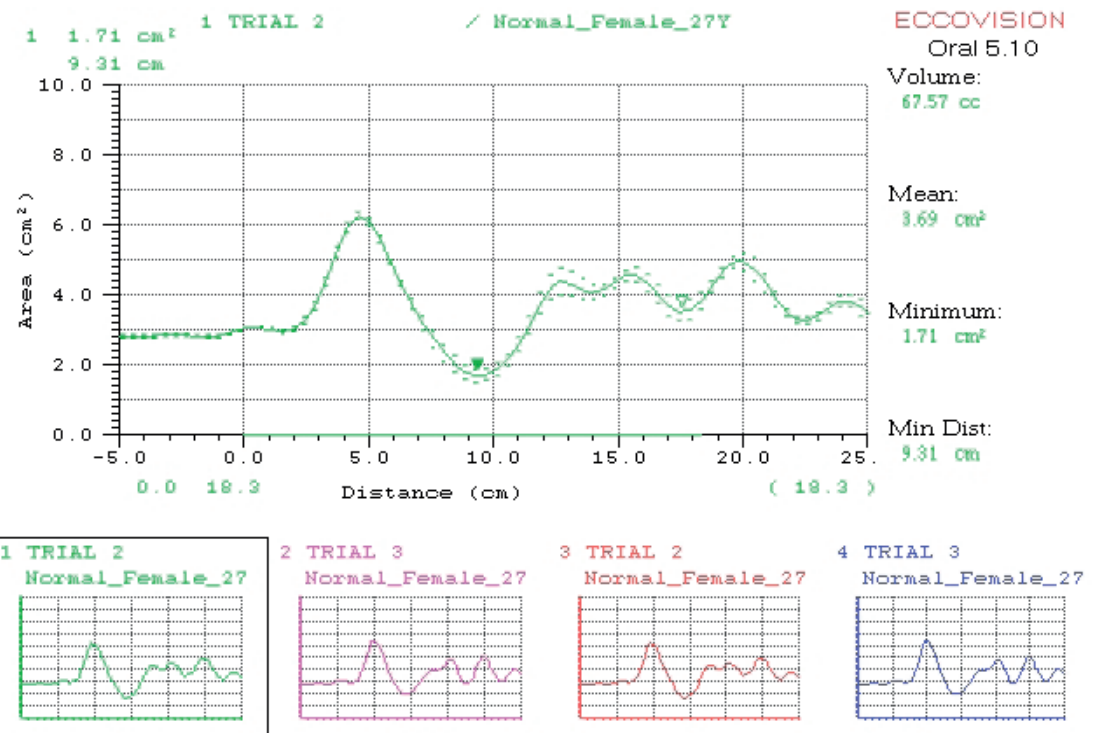

Figure 3. A normal acoustic pharyngometry image of a healthy woman. 


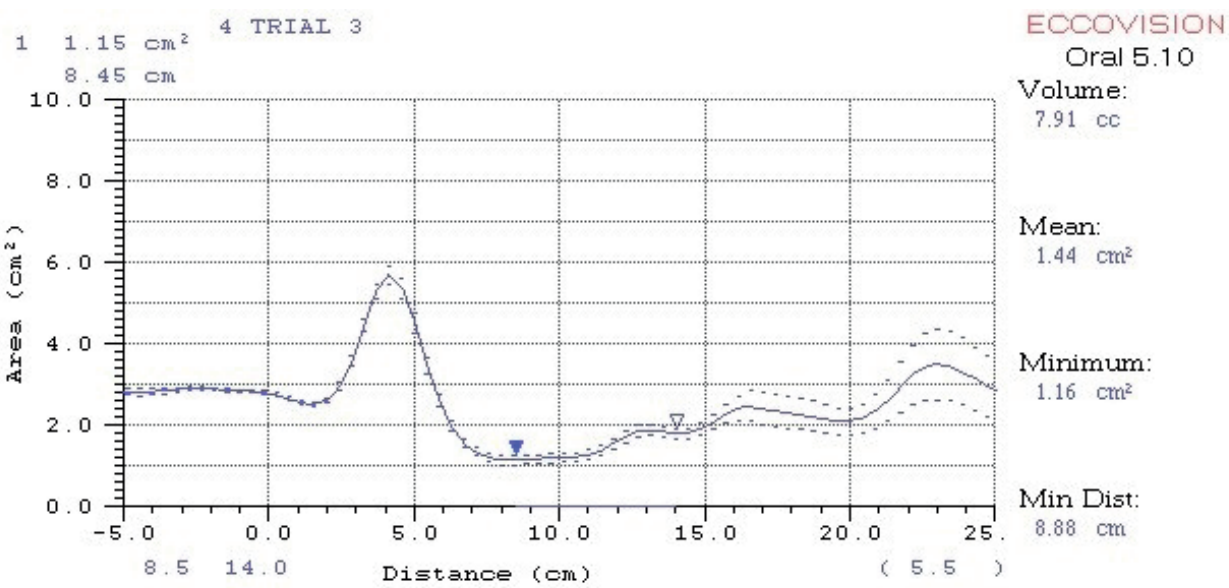

Figure 4. Acoustic pharyngometry changes in a male patient with slightly expressed pharyngeal dysfunction

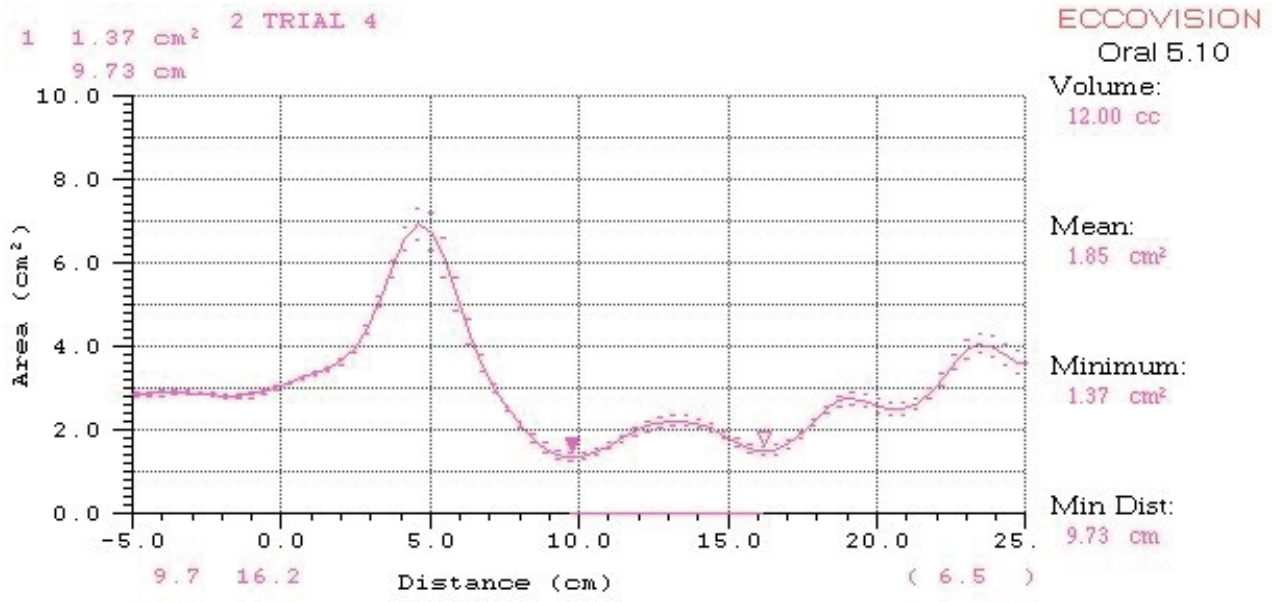

Figure 5. Acoustic pharyngometry changes in a female patient with slightly expressed pharyngeal dysfunction

The pathological acoustic pharyngometry findings in a 62-year old male patient suffering from arterial hypertension and diagnosed with severe pharyngeal dysfunction due to low soft palate, uvula elongation along with chronic hypertrophic rhinitis were demonstrated in Fig. 7.

\section{Discussion}

In the men with slight and severe pharyngeal dysfunction, there was a pharyngeal volume reduction towards the value in a healthy man by 4.65 times and 12.46 times, respectively. Concerning the mean and minimal cross-sectional areas, the corresponding figures were the following: by 2.60 times, 6.58 times, 1.96 times and 5.82 times, respectively.

In the women with slight and severe pharyngeal dysfunction, there was a pharyngeal volume reduction towards the value in a healthy woman by 5.63 times and 11.00 times, respectively. Concerning the mean and minimal cross-sectional areas, the corre32 sponding figures were the following: by 1.99 times, 3.73 times, 1.25 times and 3.56 times, respectively. These dramatic differences between the normal and pathological values of the three parameters confirmed the differential-diagnostic role of the acoustic pharyngometry concerning the extent of the pharyngeal dysfunction that underlay the sleep-disordered breathing.

The mean cross-sectional areas and airway volumes in any segments assessed by acoustic pharyngometry in 15 OSA patients are statistically significantly smaller in OSA patients than in 15 healthy controls $(p<0.05)(7)$. The minimal cross-sectional area of the upper airway at end-exhalation is measured in upright position and breathing through the mouth in 60 subjects, 35 males and 25 females at a mean age of 42 years (range, 21-81 years) (2). Their body mass index is $34 \pm 8 \mathrm{~kg} / \mathrm{m}^{2}$, mean apnea-hypopnea index is $33 \pm 30$ events/hour, and mean Epworth Sleepiness Scale score is $11 \pm 6$. In univariate logistic regression analysis, the minimal cross- 


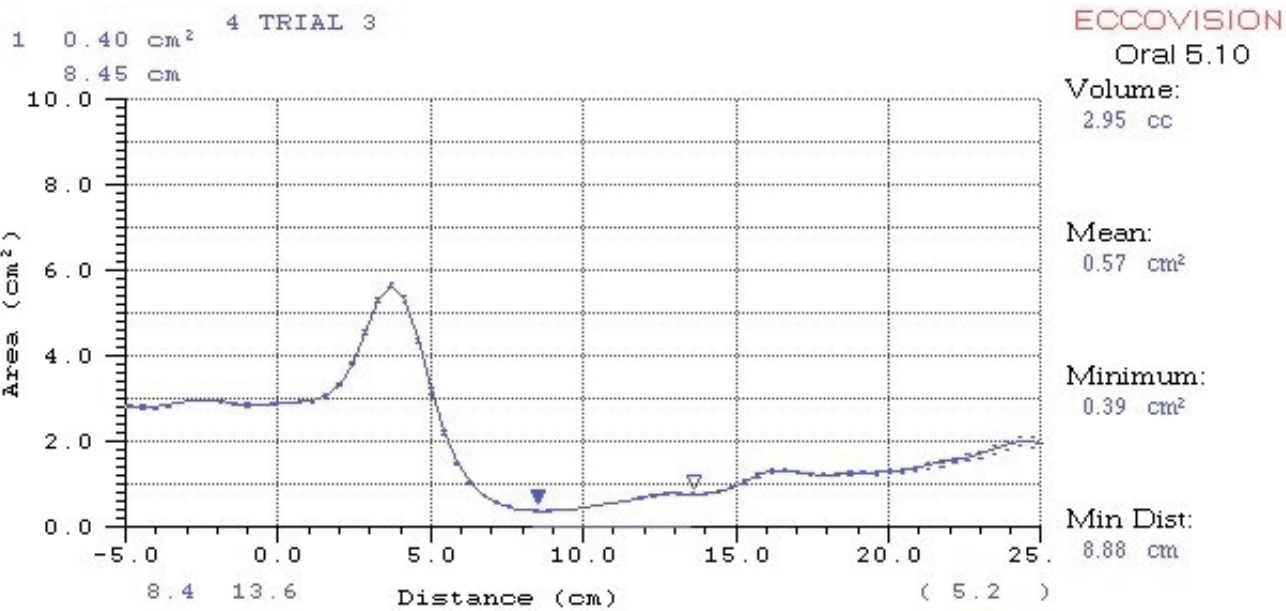

Figure 6. Acoustic pharyngometry changes in a male patient with severe pharyngeal dysfunction

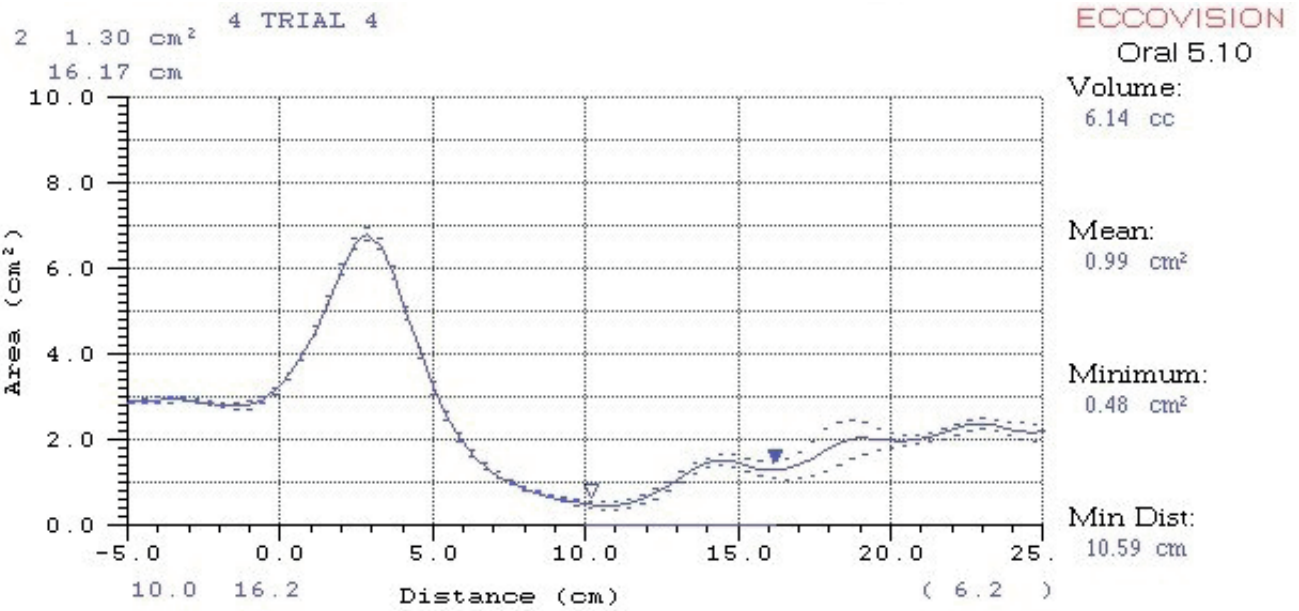

Figure 7. Acoustic pharyngometry changes in a female patient with severe pharyngeal dysfunction

sectional area is a significant predictor of mild to absent OSA (apnea-hypopnea index <15). A multivariate logistic regression model including the minimal cross-sectional area, age, gender, and neck circumference statistically significantly predicts the apnea-hypopnea index $<15$. The minimal cross-sectional area represents the only $\mathrm{s}$ ignificant independent predictor $(\mathrm{p}<0.01)$.

Among 576 subjects, 369 males and 207 females at a mean age of 57 years and with a mean body mass index of $30.3 \mathrm{~kg} / \mathrm{m}^{2}$, there are 501 patients with OSA and 75 subjects without OSA (1). The mean upper airway cross-sectional area at functional residual capacity in sitting position is significantly smaller in OSA patients than in healthy controls $\left(3.3 \mathrm{~cm}^{2}\right.$ versus $\left.3.7 \mathrm{~cm}^{2}\right)$. When controlled for age, sex, body mass index and comorbidities, the odds ratio of OSA increases for every $1-\mathrm{cm}^{2}$ decrease of the mean upper airway cross-sectional area at functional residual capacity (odds ratio of 1.62; between 1.23 and 2.13 at $95 \%$ confidence interval).
A cut-off value of $3.75 \mathrm{~cm}^{2}$, the point with the best sum of sensitivity and specificity, has a sensitivity of $73 \%$ and a specificity of $46 \%$.

Initially, 17 middle-aged, morbidly obese men have significantly lower pharyngeal cross-sectional areas at different levels of the pharynx than 20 nonobese male control subjects in the upright and supine position (8). After weight loss, both the mean pharyngeal cross-sectional area and the area at glottis level remain lower in obese than in nonobese subjects.

In 50 patients with severe obstructive sleep apnea-hypopnea syndrome (OSAHS), the distance of minimal cross-sectional area from the nostril is $2.06 \pm 0.12 \mathrm{~cm}$, the pharyngeal cross-sectional area is $0.87 \pm 0.12 \mathrm{~cm}^{2}$ and the pharyngeal cross-sectional volume is $9.24 \pm 2.31 \mathrm{~cm}^{3}$ (9). Both pharyngeal cross-sectional area and volume are statistically significantly lower in patients than in control subjects $(\mathrm{p}<0.01)$.

Among 350 normal volunteers, 271 males and 79 
females, the examinations by acoustic pharyngometry demonstrate a mean pharyngeal area of $3.194 \pm 0.311 \mathrm{~cm}^{2}$ in males and $2.814 \pm 0.331 \mathrm{~cm}^{2}$ in females as well as a mean glottic area of $1.06 \pm 0.119$ $\mathrm{cm}^{2}$ in males and $0.936 \pm 0.108 \mathrm{~cm}^{2}$ in females (6). Overall and subgroup analyses in 138 OSAHS patients demonstrate that the minimal crosssectional area of oropharyngeal lumen statistically significantly decreases $(p<0.05)$, whereas that of velopharyngeal lumen does not significantly change with mouth opening ( $>>0.05)$ (10). The relative position of tongue to soft palate is the main factor influencing upon the velopharyngeal lumen changes with mouth opening.

In 145 women at a mean age of $42.9 \pm 15.1$ years, the pharyngeal area at the oropharyngeal junction negatively correlates with body mass index, waist, hip and sagittal abdominal diameter while the mean pharyngeal area does with body mass index and sagittal abdominal diameter in orthostatic position only (11).

Among 35 consecutive male and female patients with obstructive sleep apnea syndrome examined by means of acoustic pharyngometry, body mass index and dimensions of uvula breadth and free oropharynx are significantly related to apnea-hypopnea index (12). In snoring patients with OSA, the mean apnea-hypopnea index is 25.9 events/hour and the mean pharyngeal area is $1.589 \mathrm{~cm}^{2}$ while in snorers without OSA, this index is 4,0 events/hour and the mean pharyngeal area is $2.41 \mathrm{~cm}^{2}(\mathrm{p}<0.001)(13)$. The repeatability of pharyngeal cross-sectional area measurements obtained by acoustic pharyngometry is compared between 20 adult normal volunteers, 16 men and four women at a mean age of 35.9 years, and ten adult snorers, nine men and one woman at a mean age of 36.4 years (14). In normal subjects, the mean pharyngeal cross-sectional area is 3.187 $\mathrm{cm}^{2}$ in the first session, $3.239 \mathrm{~cm}^{2}$ in the second session at the same-day, and $3.245 \mathrm{~cm}^{2}$ in the third session after seven to ten days. In the snorers, the corresponding figures are the following: $2.244 \mathrm{~cm}^{2}$, $2.237 \mathrm{~cm}^{2}$, and $2.238 \mathrm{~cm}^{2}$.

\section{Conclusion}

Our initial results indicate considerable differences in terms of the main acoustic pharyngometric parameters between healthy subjects, on the one hand, and patients presenting with slightly expressed and particularly with severe pharyngeal dysfunction causing sleep-related breathing disorders, on the other hand. A much broader acoustic pharyngometry application for the screening and early diagnosis of these socially significant disturbances among adults and children in Bulgaria is undoubtedly beneficial and should be recommended.

\section{References}

1. Agarwal SS, Jayan B, Kumar S. Therapeutic efficacy of a hybrid mandibular advancement device in the management of obstructive sleep apnea assessed with acoustic reflection technique. Indian J Dent Res. 2015;26(1):86-9. doi: 10.4103/0970-9290.156820.

2. Ahmed HM, Gemaie RA. Assessment of the airway by acoustic pharyngometry in obstructive sleep apnoea (OSA) and normal subjects: Correlation with the clinical results of endotracheal intubation. Egypt J Anaesth. 2003;19(1):85-91.

3. Busetto L, Enzi G, Inelmen EM, Costa G, Negrin V, Sergi G, et al. Obstructive sleep apnea syndrome in morbid obesity: effects of intragastric balloon. Chest. 2005;128(2):618-23. doi: 10.1378/chest.128.2.618.

4. Busetto L, Calo' E, Mazza M, De Stefano F, Costa G, Negrin V, et al. Upper airway size is related to obesity and body fat distribution in women. Eur Arch Otorhinolaryngol. 2009;266(4):559-63. doi: 10.1007/s00405-008-0773-y.

5. Deyoung PN, Bakker JP, Sands SA, Batool-Anwar S, Connolly JG, Butler JP, Malhotra A. Acoustic pharyngometry measurement of minimal cross-sectional airway area is a significant independent predictor of moderate-to-severe obstructive sleep apnea. J Clin Sleep Med. 2013;9(11):1161-4. doi: 10.5664/jcsm.3158.

6. Gelardi M, Del Giudice AM, Cariti F, Cassano M, Farras AC, Fiorella ML, Cassano P. Acoustic pharyngometry: clinical and instrumental correlations in sleep disorders. Braz J Otorhinolaryngol. 2007;73(2):257-65. doi: 10.1016/s1808-8694(15)31075-2.

7. $\mathrm{Hu} \mathrm{B}$, Ye J, Yin G, Zhang Y. The influential factors on the morphological changes of upper airway associated with mouth opening. Laryngoscope. 2018;128(12):2902-9. doi: 10.1002/lary.27212.

8. Hu J, Lang J, Liao J, Yu W, Zhang J, Jiang T, et al. OSAHS patient gas up-take cross-sectional area nasopharynx sound reflection examination and significance. Lin Chung Er Bi Yan Hou Tou Jing Wai Ke Za Zhi. 2011;25(20):936-8 (in Chinese).

9. Jung DG, Cho HY, Grunstein RR, Yee B. Predictive value of Kushida index and acoustic pharyngometry for the evaluation of upper airway in subjects with or without obstructive sleep apnea. J Korean Med Sci. 2004;19(5):662-7. doi: 10.3346/jkms.2004.19.5.662.

10. Kamal I. Acoustic pharyngometry patterns of snoring and obstructive sleep apnea patients. Otolaryngol Head Neck Surg. 2004;130(1):58-66. doi: 10.1016/j.otohns.2003.08.008.

11. Kamal I. Normal standard curve for acoustic pharyngometry. Otolaryngol Head Neck Surg. 2001;124(3):323-30. doi: 10.1067/ mhn.2001.113136.

12. Kamal I. Test-retest validity of acoustic pharyngometry measurements. Otolaryngol Head Neck Surg. 2004a;130(2):223-8. doi: 10.1016/j. otohns.2003.08.024.

13. Kendzerska T, Grewal M, Ryan CM. Utility of acoustic pharyngometry for the diagnosis of obstructive sleep apnea. Ann Am Thorac Soc. 2016;13(11):2019-2026. doi: 10.1513/AnnalsATS.201601-056OC

14. Thulesius HL, Thulesius HO, Jessen M. Pharyngometric correlations with obstructive sleep apnea syndrome. Acta Otolaryngol. 2004;124(10):1182-6. doi: 10.1080/00016480410018232. 